\title{
Effects of Nitrogen and Phosphorus on Biochemical Composition of Microalgae Polyculture Harvested from Phycoremediation of Piggery Wastewater Digestate
}

\author{
William Michelon ${ }^{1} \cdot$ Marcio Luis Busi Da Silva ${ }^{2}$. \\ Melissa Paola Mezzari ${ }^{3}$ - Mateus Pirolli ${ }^{1}$. \\ Jean Michel Prandini ${ }^{1} \cdot$ Hugo Moreira Soares ${ }^{1}$
}

Received: 27 October 2015 / Accepted: 8 December 2015 /

Published online: 22 December 2015

(C) Springer Science+Business Media New York 2015

\begin{abstract}
The effects of nitrogen (N) and/or phosphorus (P) starvation on the biochemical composition of native microalgae Chlorella spp. polyculture obtained from the phycoremediation of swine wastewaters were investigated. Microalgae-specific growth rate of 1.2 day $^{-1}$ was achieved $\left(30.3 \mathrm{mg} \mathrm{L}^{-1}\right.$ day $\left.{ }^{-1}\right) . \mathrm{PO}_{4}{ }^{-2}$ and $\mathrm{NH}_{3}$ were completely removed from swine digestate effluent after 3 and 11 days, respectively. Microalgae harvested immediately after nutrient removal showed high protein (56-59\%) and carbohydrate (25-34 \%) but low lipid (1.8-3\%) contents. Depletion of N or P alone stimulated carbohydrate production at the expenses of proteins. Significant lipid accumulation from $3 \% \pm 0.5$ to $16.3 \% \pm 0.8$ was reached only after 25 days following $\mathrm{N}$ and $\mathrm{P}$ starvation as
\end{abstract}

Marcio Luis Busi Da Silva

marcio.busi@embrapa.br

William Michelon

willian.michelom@posgrad.ufsc.br

Melissa Paola Mezzari

melissa.mezzari@unoesc.edu.br

Mateus Pirolli

pirollimateus@gmail.com

Jean Michel Prandini

Jeanprandini@hotmail.com

Hugo Moreira Soares

soares@enq.ufsc.br

1 Department of Chemical Engineering, Federal University of Santa Catarina, Florianópolis, SC 88040-900, Brazil

2 EMBRAPA Swine and Poultry, P.O. Box 321, Concórdia, SC 89700-000, Brazil

3 Biotechnology and Sciences Program, West University of Santa Catarina, Videira, SC 89560-000, Brazil 
demonstrated by Nile red-stained cells. Regarding to the effects of harvesting methods on cellular biochemical composition, circumstantial evidences indicate that coagulationflocculation with tannin may lead to lower protein and lipid amounts but increased carbohydrate content $(p<0.01)$ as compared to centrifugation.

Keywords Carbohydrate $\cdot$ Lipid $\cdot$ Microalgae $\cdot$ Phycoremediation $\cdot$ Protein $\cdot$ Swine wastewater

\section{Introduction}

The use of phycoremediation as a tertiary treatment approach to remove nutrients $(\mathrm{N}$ and $\mathrm{P})$ from swine wastewaters has been extensively reported [1-3] with promising results $[4,5]$. The integration of microalgae biomass production concomitantly to wastewater treatment seems essential to support the economic feasibility of microalgae-based industries [6]. The resulting microalgae obtained from this algae-based wastewater process could serve as feedstock for food processing [7], biogas [3], biodiesel [8], and/or for bioethanol/biohydrogen production [9]. Additionally, several other high-value by-products of biotechnological interest could be obtained such as carotenoids and omega-3-rich oils [7].

Microalgae can accumulate considerable quantities of carbohydrates, proteins, and/or lipids $[9,10]$. Changes in microalgae biochemical composition are likely to occur as a result of variations in $\mathrm{pH}$ [11], temperature [12], light, salinity [13], and metal contents [14]. Likewise, alternative methods of cultivation (i.e., autotrophic vs heterotrophic) [15] and harvesting [16] can also interfere with cellular biochemical constitution. Regarding to the effects of nutrients, studies demonstrated that $\mathrm{N}$ and/or $\mathrm{P}$ limitation in growth media causes metabolism alterations that induce lipid accumulation $[17,18]$. Despite of several studies made in attempt to understand the potential effects of $\mathrm{N}$ and/or $\mathrm{P}$ limitations on microalgae biochemical composition changes, the phenomena seem to be species dependent [9]. Moreover, it is worth mentioning that most of related studies (if not all) were conducted using sterile synthetic culturing media and under laboratory-controlled conditions with isolated species-specific microalgae strains. Thus, little attention has been placed on how nutrient limitations could affect intracellular biochemical structure in microalgae polycultures grown in non-sterile raw swine wastewater effluents at conditions resembling field-scale wastewater treatment operations. Characterization of protein, carbohydrate, and lipid contents from this polyculture biomass is desirable because it will ultimately dictate the rationale behind the applicability usefulness of this particular agricultural algae-based wastewater treatment source of biomass [15].

Harvesting process can also play an important role on microalgae biochemical composition because it can affect both the quantity and the quality of the final products as well as the economical feasibility of microalgae as feedstock. There are various mechanical as well as chemical methods of algal biomass harvesting including centrifugation, flocculation, filtration and screening, gravity sedimentation, and flotation. For instance, microalgae separated by foam flotation showed significantly higher lipid content than cells harvested by centrifugation [19]. However, other studies concluded that no significant differences exist in lipid content from cells of Botryococcus braunii when harvested by either centrifugation or chemical precipitation using different coagulants and $\mathrm{pH}$ adjustments [16]. A similar study demonstrated that lipid content was not affected by neither anionic nor cationic flocculants used for separation of Nannochloropsis oculata and Thalassiosira weissflogii; however, differences in fatty acid composition profile were noticed [20]. Therefore, the potential role that different 
harvesting processes can have on microalgae biochemical composition changes still remains poorly understood.

In this work, laboratory- and near-field pilot-scale experiments were performed to determine the removal efficiency of ammonia and phosphorus from swine wastewater digestate by phycoremediation. The resulting microalgae polyculture biomass, mainly composed by Chlorella spp., was subjected to intracellular biochemical analyses for quantification of proteins, carbohydrates, and lipids. Emphasis was placed on determining the potential effects of nitrogen- and/or phosphorus-limited conditions on cellular protein, carbohydrate, and lipid composition changes. Ancillary, the effects of centrifugation and chemical coagulation-flocculation on microalgae biochemical composition were also addressed.

\section{Material and Methods}

\section{Experimental Setup}

Lab-scale photobioreactors (PBRs) were used to evaluate ammonia and phosphorus removal efficiencies from swine wastewater digestate by phycoremediation. Twelve-liter (20 cm Ø ID) PBRs were maintained at room temperature $\left(23{ }^{\circ} \mathrm{C}\right)$, exposed to 12 -h light

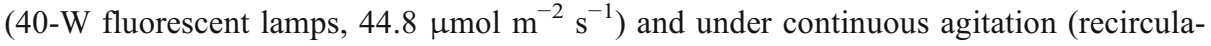
tion aquarium pumps, Sarlobetter).

The microalgae consortium used as inoculum was obtained directly from a facultative open pond used as tertiary treatment process to remove nutrients from a previously digested swine wastewater effluent at EMBRAPA swine and poultry facilities (Concórdia, Santa Catarina, Brazil). Microscopic analyses $(\times 1000$; Nikon Eclipse E200 equipped with 1.3-MP resolution camera, Moticam 1000) revealed the predominance of Chlorella spp. in the inoculum. Molecular analyses were further conducted to aid identification. In this case, total genomic DNA was isolated from $30 \mathrm{mg}$ of fresh algal biomass using the CTAB DNA extraction protocol [21]. Sequences were determined bidirectionally for at least two different amplicons using the BigDye Terminator v.3.1 Cycle Sequencing Kit on the automated DNA sequencer ABI 3130. Primers used for amplification of nuITS2 (ITS1: F-5'-AGGAGAAGTCGTAAC AAGGT-3' and ITS4R: R-5'-TCCTCCGCTTATTGATATGC-3') [22] were annotated and trimmed using the ITS2 annotation tool available at ITS2 Database [23]. The nuITS2 sequences were submitted to BLASTN for comparisons against sequences deposited at GenBank. For similarity searches, the rbcL gene sequences that encode the large subunit of the $\mathrm{CO}_{2}$-fixing enzyme RuBisCO were submitted to the Barcode of Life Data Systems (BOLD Systems) using the plant identification tool and primers RH1: F-5'-TGTCACCACAAACA GAAACTAAAGC-3' and rbcL 1385: R-5'- AATTCAAATTTAATTTCTTTCC-3' [24]. Chlorella spp. were found to be dominant in the inoculum (rbcL of $93.3 \%$ and ITS2 of $95 \%$ ) corroborating with morphological analysis. The strain was isolated and deposited in the collection of photosynthetic microorganisms for Agroenergy Research at Embrapa (Brasília, DF, Brazil) under access number Embrapa LBA\#31 (IAN193.096).

Experiments were performed in duplicate and inoculated with approximate microalgae concentration dry weight $\left(30 \% v / v\right.$ or $\left.\cong 70 \mathrm{mg} \mathrm{L}^{-1}\right)$.

Experiments were batch fed using diluted $(6 \% v / v)$ non-sterile swine wastewater digestate effluent from an in situ anaerobic upflow sludge blanket reactor (UASB) located 
at EMBRAPA swine wastewater treatment facilities (Concórdia, SC, Brazil). Using higher volumes of UASB effluent beyond this selected dilution was commonly accompanied by increased turbidity that affected light penetration [2] and consequently hindered microalgae growth (data not shown). The physicochemical characteristics of the raw UASB effluent tested are shown in Table 1.

\section{Analytical Methods}

Samples were monitored daily for $\mathrm{pH}$ ( $\mathrm{pH}-\mathrm{mV}$, Hanna Instruments, Inc.), temperature, and dissolved oxygen (DO) (Hanna, 9146) as well as turbidity (Hach Model 2100P). Potentiometric analysis using a selective electrode method was used to measure ammonia $\mathrm{NH}_{3}-\mathrm{N}$ [25]. Nitrite $\mathrm{NO}_{2}{ }^{-}-\mathrm{N}$ and nitrate $\mathrm{NO}_{3}{ }^{-}-\mathrm{N}$ concentrations were determined by flow injection analysis system (FIAlab-2500). Phosphorus was quantified by the ascorbic acid colorimetric method using a spectrophotometer UV-visible (Varian, Inc. Cary ${ }^{\circledR} 50$ ) [25]. Total organic and inorganic carbon was measured in a TOC analyzer (Multi C/N 2100, Analytik Jena). Alkalinity (as $\mathrm{mg} \mathrm{CaCO}_{3}$ ) was determined by automatic titration (Metrohm 848 Titrino Plus). Total solid content was determined by gravimetric assay [25].

\section{Microalgae Growth}

A satisfactory correlation between chlorophyll $a$ and biomass dry weight was obtained $\left(r^{2}=0.99\right)$ (Fig. 1). Thus, the concentration of microalgae in the reactors was estimated by chlorophyll $a$ content according to methanol extraction protocol [26]. Microalgae-specific growth $\left(\mu\right.$, day $\left.^{-1}\right)$ was obtained from exponential growth phase using regression analysis $\left[\left(\ln X / \ln X_{0}\right) / t\right]$, where $X_{0}$ and $X$ were biomass dry weight concentrations $\left(\mathrm{mg} \mathrm{L}^{-1}\right)$ at the initial time and after $n$ days, respectively. Microalgae biomass productivity $P$, as milligram per liter per day, was estimated with Eq. (1):

$$
P=\left(X_{t}-X_{0}\right) /\left(t_{x}-t_{0}\right)
$$

where $X_{0}$ and $X$ were the biomass dry weight concentrations $\left(\mathrm{mg} \mathrm{L}^{-1}\right)$ at the initial time and after $n$ days, respectively.

Table 1 Physicochemical characteristics of the raw swine wastewater digestate used as culturing media for microalgae growth

\begin{tabular}{ll}
\hline Parameters & UASB effluent \\
\hline $\mathrm{pH}$ & $7.7 \pm 0.2$ \\
$\mathrm{PO}_{4}{ }^{3-}-\mathrm{P}\left(\mathrm{mg} \mathrm{L}^{-1}\right)$ & $160 \pm 4.6$ \\
$\mathrm{NH}_{3}-\mathrm{N}\left(\mathrm{mg} \mathrm{L}^{-1}\right)$ & $750.4 \pm 49.7$ \\
$\mathrm{NO}_{2}-\mathrm{N}\left(\mathrm{mg} \mathrm{L}^{-1}\right)$ & $4 \pm 6.8$ \\
$\mathrm{NO}_{3}{ }^{-}-\mathrm{N}\left(\mathrm{mg} \mathrm{L}^{-1}\right)$ & - \\
$\mathrm{TOC}\left(\mathrm{g} \mathrm{L}^{-1}\right)$ & $1.9 \pm 0.14$ \\
$\mathrm{Alkalinity}\left(\mathrm{g} \mathrm{L}^{-1}\right.$ as $\left.\mathrm{CaCO}_{3}\right)$ & $1.9 \pm 0.09$ \\
Turbidity $(\mathrm{NTU})$ & $1063 \pm 18.8$ \\
TS $\left(\mathrm{g} \mathrm{L}^{-1}\right)$ & $9.8 \pm 0.2$ \\
\hline
\end{tabular}

TOC total organic carbon, TS total solids 
Fig. 1 Correlation between biomass dry weight and chlorophyll $a$ concentrations

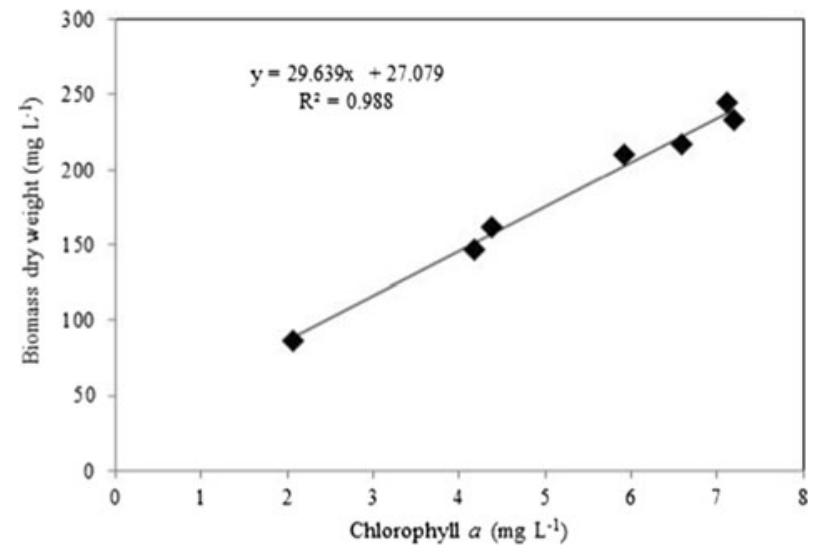

\section{Microscopy}

Nile red staining was used to monitor the accumulation of intracellular lipid over time [27]. Briefly, $2 \mathrm{~mL}$ sample aliquots were withdrawn from the reactors and centrifuged (3500g for $1 \mathrm{~min}$ ) (Scilogex, D3024R). The obtained cell pellet was resuspended in $450 \mu \mathrm{L}$ ultrapure water containing $50 \mu \mathrm{L}$ DMSO. Dye solution containing $0.25 \mathrm{mg} \mathrm{mL}^{-1}$ Nile red (9-diethylamino-5H-benzo $[\alpha]$ phenoxa-phenoxazine-5-one) in dimethyl sulfoxide (DMSO) was added to a final concentration of $0.3 \mathrm{mg} \mathrm{mL}^{-1}$. Sample was then incubated in the dark and at room temperature for $30 \mathrm{~min}$. Cells were observed using an AxioObserver.Z1 fluorescent microscope (Zeiss, BR), and images were obtained using a $\times 100$ oil immersion lens. Nile red fluorescent detection was achieved with excitation wavelength of $488 \mathrm{~nm}$ and emission at 505-550 nm. All compounds used were of analytical grade (Sigma-Aldrich, USA).

\section{Harvesting Methods}

Two conventional microalgae separation methods were tested for determination of its potential to alter microalgae cellular biochemical composition. Four hundred liters of culturing media containing the microalgae biomass grown in 500-L reservoirs ("Cellular Biochemical Composition" section) was centrifuged (EVODOS, T10, Netherlands) or chemical flocculated using a cationic organic polymer tannin as previously described [28]. Briefly, $11 \mu \mathrm{g} \mathrm{L}^{-1}$ of tannin was added at a fixed stir velocity of $50 \mathrm{rpm}$ for $5 \mathrm{~min}$ followed by sedimentation time of $15 \mathrm{~min}$. This method proved to recover $>95 \%$ of microalgae biomass at neutral $\mathrm{pH}$.

\section{Cellular Biochemical Composition}

To determine the effects of stress-induced nitrogen and/or phosphorus limitations on microalgae protein, carbohydrate, and lipid biochemical composition changes, microalgae were first grown in 400-L culturing media inside a 500-L circular reservoirs $(121.2 \mathrm{~cm} \varnothing$ i.d.; 58.4-cm height) in a greenhouse exposed to natural sunlight (321.5 
$\pm 411.4 \mu \mathrm{mol} \mathrm{m} \mathrm{m}^{-2} \mathrm{~s}^{-1}$ ) and under ambient average temperature of $31.7 \pm 16.3{ }^{\circ} \mathrm{C}$ (Table 2). The same inoculum source maintained in the laboratory for the phycoremediation experiments ("Experimental Setup" section) was also used to inoculate these field-scale reactors. Similarly, wastewater source and dilution established in the phycoremediation tests were replicated for field-scale experiments. Reservoirs were kept under continuous agitation using submersible aquarium pumps.

After 7 days following inoculation, $400 \mathrm{~L}$ of culturing media containing microalgae biomass was harvested via centrifugation and cells resuspended in fresh 400-L nutrientfree water. To verify the influence of each nutrient on cellular biochemical composition, nutrient-free water was artificially amended with either $50 \mathrm{mg} \mathrm{N}-\mathrm{NO}_{3}{ }^{-} \mathrm{L}^{-1}$ or $10 \mathrm{mg} \mathrm{P}-$ $\mathrm{PO}_{4}{ }^{2-} \mathrm{L}^{-1}$. To avoid nutrient exacerbation during the tests, $\mathrm{N}$ or $\mathrm{P}$ was continuously monitored and replenished accordingly. After 25 days, the cells were harvested by centrifugation (EVODOS, T10, Netherlands) and the biomass collected for further analysis.

Prior to analysis, the collected biomass was dried in an oven (Fanem 520, BR) at $105^{\circ} \mathrm{C}$ for $5 \mathrm{~h}$ and then weighed. Protein, carbohydrate, and lipid contents were reported as percentage of total biomass dry weight content. The cellular lipid content was determined by ether extraction (Ankom XT15) [33]. Protein content was measured by the combustion method (Leco FP-528) [34]. Ash content was determined according to the Brazilian Compendium of Animal Nutrition, method 36 [35]. Carbohydrate was determined by subtracting total cell dry weight from the measured lipid, protein, and ash concentrations [36].

\section{Statistical Analysis}

To determine if two sets of data were significantly different from each other, data were analyzed using one-way analysis of variance (ANOVA) using OriginPro 8. A significant difference was considered at the level of $p<0.05$.

Table 2 Variations in protein (PT), carbohydrate $(\mathrm{CH})$, and lipid (LP) content percentages in microalgae as function of $\mathrm{N}$ - and/or P-limiting conditions as compared to microalgae grown in culturing media supplied with $\mathrm{N}$ and $\mathrm{P}$

\begin{tabular}{|c|c|c|c|c|c|c|c|c|c|c|}
\hline \multirow[t]{3}{*}{ Microalgae species } & \multicolumn{9}{|c|}{ Nutrients } & \multirow[t]{3}{*}{ References } \\
\hline & \multicolumn{3}{|c|}{$\mathrm{N}$ and $\mathrm{P}$ limited } & \multicolumn{3}{|l|}{$\mathrm{N}$ limited } & \multicolumn{3}{|c|}{ P limited } & \\
\hline & PT & $\mathrm{CH}$ & LP & PT & $\mathrm{CH}$ & LP & PT & $\mathrm{CH}$ & LP & \\
\hline Chlorella vulgaris & - & - & $25-43$ & (-) $33-25$ & $28-42$ & $3-39$ & - & - & $13-25$ & {$[9,18,29]$} \\
\hline Chlorella zofingiensis & - & - & 20 & (-) 17 & $11-16$ & $8-41$ & - & - & $17-21$ & {$[8]$} \\
\hline Chlorella sp. & - & - & 9 & - & - & 7 & - & - & 1 & {$[17]$} \\
\hline Scenedesmus obliquus & (-) 38 & 17 & 21 & (-) 26-43 & $13-27$ & $11-26$ & $(-) 8$ & 2 & 2 & {$[10,30]$} \\
\hline Chlamydomonas sp. & - & - & - & 14 & 13 & 7 & - & - & 9 & {$[31]$} \\
\hline Isochrysis galbana & - & - & - & - & - & - & - & - & 29 & {$[32]$} \\
\hline Chlorella spp. & (-) 37 & 32 & 13 & $(-) 7$ & 10 & 2 & $(-) 9$ & 15 & 1 & This study \\
\hline
\end{tabular}

$(-)$ Decrease 


\section{Results and Discussion}

\section{Phycoremediation}

Laboratory- and near-field pilot-scale batch reactors were utilized in this work to simulate algae-based swine wastewater treatment processes on the removal of ammonia and phosphorus from UASB digestate. The resulting microalgae biomass produced at the end of phycoremediation was harvested and analyzed for protein, carbohydrate, and lipid contents. Changes in microalgae communities over time were indistinguishable as indicated by microscopic analyses performed throughout the experimental time frame. However, variations in populations should not be disconsidered. Cultivation and maintenance of specific microalgae species at field-scale operations can be quite challenging due to variations in environmental conditions and system's intrinsic propensity for cross contamination. Despite of these implications, however, the results are still relevant to anticipate biochemical constitution of microalgae polyculture biomass obtained from phycoremediation of swine wastewaters at field-scale operations.

Microalgae biomass dry weight was estimated by measurements of chlorophyll $a$ (Fig. 1a). The highest concentration $\left(6.1 \mathrm{mg} \mathrm{L}^{-1}\right.$ equivalent to approximately $207.9 \mathrm{mg} \mathrm{L}^{-1}$ as biomass dry weight) was obtained after 4 days of the experiment and then reached a plateau. The faster $\mathrm{N}$ and $\mathrm{P}$ removal rates occurred concomitantly with microalgae exponential growth phase (Fig. 1a-c). The beginning of the stationary phase occurred simultaneously with the depletion of phosphorus needed for cell synthesis. The estimated specific growth rate of 1.2 day $^{-1}$ was within expected value for microalgae consortia containing Chlorella spp. grown in diluted piggery wastewaters, i.e., 1.4 day $^{-1}[1]$.

Phosphate was completely removed (100\%) from the PBRs after 3 days of experiment (Fig. 2b). It is worth mentioning that phosphorus removal efficiencies achieved in this study were comparatively higher than previously reported for other Chlorella spp. grown in diluted piggery effluents, i.e., 8 to $88.5 \%$ [2].

During phycoremediation, ammonia was completely removed after 11 days of experiment (Fig. 2c). This result corroborates with previously reported studies conducted under similar experimental conditions using Chlorella sp. [2]. It is unlikely that the ammonia removed in the PBR experiments was solely attributed to microalgae assimilation. The appearance of nitrite and nitrate metabolites after 7 days of experiment (Fig. 2c) suggests the occurrence of bacterial-mediated nitrification and denitrification activities as previously demonstrated and discussed [1]. The increased microalgae biomass led to high concentrations of oxygen-derived photosynthesis from 2 to $8.5 \mathrm{mg} \mathrm{L}^{-1}$ (Fig. 2a). The presence of high dissolved oxygen stimulates nitrification/denitrification metabolic pathways [1]. At the beginning of the experiments, however, anaerobic conditions were encountered probably due to insufficient microalgae biomass needed to overcome the biological oxygen demand (BOD) exerted by heterotrophic microorganisms present in the non-sterile culturing media $[1,2]$.

It is worth mentioning that the utilization of clean water to dilute the raw digestate effluent may be uneconomic and unsustainable. Nonetheless, low-turbidity nutrient-free water can be obtained at the end of phycoremediation process and recycled as previously demonstrated [28]. Reuse of water minimizes costs and associated environmental concerns on natural resource constraints as a result of cultivation system at industrial scales. 
Fig. 2 Chlorophyll $a$ and dissolved oxygen (a); phosphorus (b); and ammonia, nitrate, and nitrite (c) concentration profiles measured in photobioreactors over time. Bars depict standard errors

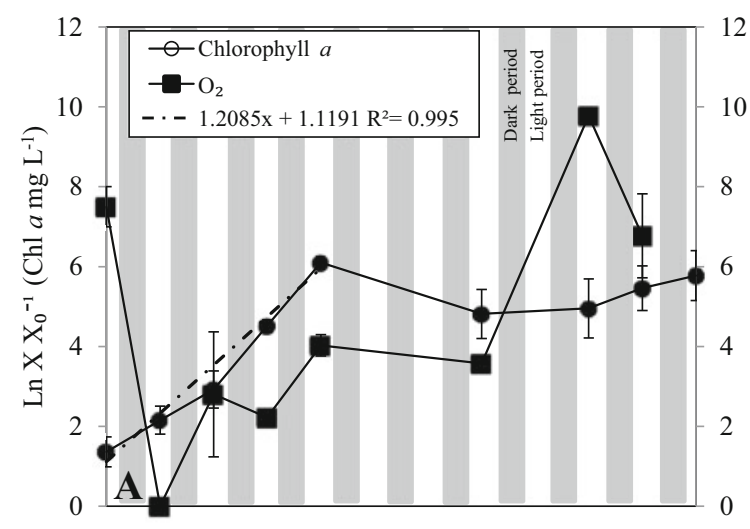

12

10

8

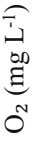
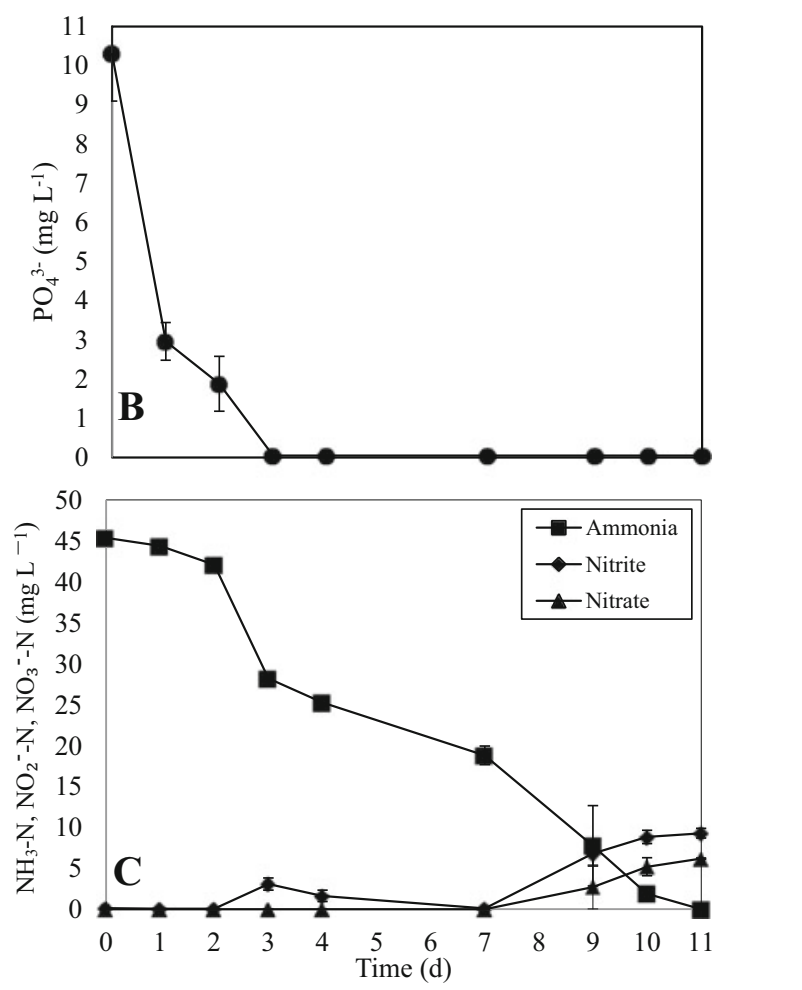

\section{Harvesting Effects on Microalgae Biochemical Composition}

The effects of two conventional harvesting methods namely chemical coagulation/flocculation and mechanical centrifugation were assessed to anticipate its influence on biochemical composition changes of microalgae polyculture grown on piggery wastewaters (Table 3). Microalgae biomass harvested by chemical coagulation using the organic cationic polymer tannin showed $56.1 \pm 0.4,34.4 \pm 0.4$, and $1.8 \pm 0.6 \%$ of protein, carbohydrate, and lipid contents, respectively (Table 3 ). Microalgae biomass harvested by mechanical centrifugation showed the following: $58.9 \pm 1.3,25.2 \pm 0.9$, and $3 \pm 0.5 \%$ of protein, carbohydrate, and lipid 
Table 3 Average ( \pm std dev) of protein, carbohydrate, and lipid contents (\%) in polyculture microalgae biomass as function of coagulation-flocculation or centrifugation harvesting methods

\begin{tabular}{|c|c|c|c|c|}
\hline \multirow[t]{2}{*}{ Harvesting method } & \multicolumn{4}{|c|}{ Content $(\%)$} \\
\hline & Protein & Carbohydrate & Lipid & Ash \\
\hline Coagulation-flocculation & $56.1 \pm 0.4$ & $34.4 \pm 0.4$ & $1.8 \pm 0.6$ & $7.7 \pm 0.5$ \\
\hline Centrifugation & $58.9 \pm 1.3$ & $25.2 \pm 0.9$ & $3 \pm 0.5$ & $12.8 \pm 0.6$ \\
\hline$p$ & 0.027 & $<0.001$ & 0.049 & $<0.001$ \\
\hline
\end{tabular}

contents, respectively (Table 3$)$. Carbohydrate content was significantly lower $(p<0.001)$ in biomass harvested by centrifugation compared to coagulation/flocculation. This could be attributed to the physical centrifugation process triggering cellular stress [27]. However, protein and lipid contents were higher $(p<0.05)$ in biomass harvested by centrifugation as compared to coagulation/flocculation.

\section{Nutrient Effects on Microalgae Biochemical Composition}

The effects of nitrogen and/or phosphorus starvation were investigated as potential metabolic engineering strategy to alter biochemical composition of microalgae polyculture biomass during phycoremediation of swine wastewater digestate. It should be emphasized that the effects of nutrient starvation on microalgae cellular physiology and morphology have already been discussed $[8,17,37,38]$. Whereas these studies certainly contributed to understand the physiological phenomena, the applicability of these concepts on microalgae polyculture from algae-based wastewater tertiary treatments has not been fully addressed to answer the industrial expectations from such source of biomass. These findings become relevant to practitioners since there are inconclusive data on literature regarding to the effects of $\mathrm{N}$ and/or $\mathrm{P}$ on lipid accumulation.

Microalgae biomass harvested immediately after depletion of nutrients from the culturing medium showed high protein and carbohydrate but low lipid content (referred to control hereafter; Table 4). This could be attributed to the intrinsic characteristics of the nutrient-rich swine wastewater digestate not offering metabolic advantages for lipid biosynthesis by microalgae [10]. When these cells were exposed to 25 days under $\mathrm{N}$-deficient culturing medium, but in the presence of phosphate, relevant changes in biomass biochemical composition were observed (Table 4). Lipids increased from $3 \pm 0.5$ to $4.8 \pm 1.5$, and carbohydrates

Table 4 Average ( \pm std dev) of protein, carbohydrate, and lipid contents $(\%)$ in polyculture microalgae biomass as function of $\mathrm{N}-, \mathrm{P}-$, or $\mathrm{N}$ - and P-limited conditions in comparison to control

\begin{tabular}{llllllllll}
\hline Nutrients condition & \multicolumn{1}{l}{ Content (\%) } \\
\cline { 2 - 9 } & Protein & $p$ & Carbohydrate & $p$ & Lipid & $p$ & Ash & $p$ \\
\hline Control & $58.9 \pm 1.3$ & & $25.2 \pm 0.9$ & & $3 \pm 0.5$ & & $12.8 \pm 0.6$ & \\
N limited & $52.3 \pm 1.8$ & 0.016 & $35.3 \pm 4.1$ & 0.0218 & $4.8 \pm 1.5$ & 0.126 & $7.6 \pm 0.7$ & 0.003 \\
P limited & $49.7 \pm 0.1$ & 0.002 & $40.4 \pm 0.1$ & $<0.001$ & $4.1 \pm 0.2$ & 0.052 & $5.9 \pm 0.0$ & $<0.001$ \\
N and P limited & $22 \pm 3$ & $<0.001$ & $56.8 \pm 3.2$ & $<0.001$ & $16.3 \pm 0.8$ & $<0.001$ & $4.8 \pm 0.6$ & $<0.001$ \\
\hline
\end{tabular}


increased from 25.2 to $35.3 \pm 4.1 \%$, whereas proteins decreased from $58.9 \pm 1.3$ to 52.3 $\pm 1.8 \%$. The increase in carbohydrate and lipids seemed to be accompanied by a concomitant decrease in protein content. These findings are in agreement with previous reports that demonstrated that under N-limited conditions, lipid and carbohydrate contents were improved in cells of Neochloris oleoabundans HK-129 [14], Chlorella vulgaris [9], Scenedesmus obliquus CNW-N [10, 30], Nannochloropsis sp., and Tetraselmis suecica [39] (Table 2). The accumulations of lipids and carbohydrates were not surprising because these are the two major carbon constituents that accumulate in response to stress conditions [8]. Under N-limited conditions, microalgae can trigger its metabolism by producing carbohydrates and/or lipids for energy reserves needed to overcome periods of nutrient limitations. Protein/peptides are forced to be converted into lipids/carbohydrates $[10,14]$, and protein synthesis is inhibited since nitrogen is a major element in its composition [40]. The Kreb's cycle is also interrupted, thus contributing to fatty acid formation [41].

Phosphorus is used for the formation of nucleic acids, membranes, and energy (ATP) in cells [40]. Deficiency of this nutrient can lead to variations in cellular biochemical synthesis [32]. Under N-augmented, but P-limited conditions (Table 4), the fraction of carbohydrate, lipid, and protein contents in the biomass was as follows: $40.4 \pm 0.1,4.1 \pm 0.2$, and 49.7 $\pm 0.1 \%$, respectively. Despite of decreased protein content from 58.9 to $49.7 \%$ and the marginal increment of lipid content from 3 to $4.1 \%$, a noticeable enhancement in carbohydrate was also observed (from 25.2 to $40.4 \%$ ) when compared to control (Table 4). Corroborating with these findings, Chlorella sp. cultivated under low phosphorus concentrations (i.e., $32 \mu \mathrm{M}$ ) stimulated lipid accumulation (up to $23.6 \%$ ) as compared to cells grown in the presence of $240 \mu \mathrm{M}$ of phosphorus [17]. In this latter study, protein content did not change significantly although its reduction was observed over time, and carbohydrate storage was inversely proportional to the phosphorus concentration tested. Results obtained with Skeletonema costatum showed that lipid content increased under P limitation but not for $\mathrm{N}$ limitation, whereas carbohydrate accumulated under both $\mathrm{N}$ - and P-deficient conditions and

Fig. 3 In the absence of both $\mathrm{N}$ and $\mathrm{P}$ nutrients, the microalgae culture dominated by Chlorella spp. became yellowish over time (1, 10, 16, 20, and 25 days). The intracellular lipid content increased significantly as demonstrated with Nile red, a neutral dye for lipids ( $\times 1000$ magnification). The bar markers represent $5 \mu \mathrm{m}$
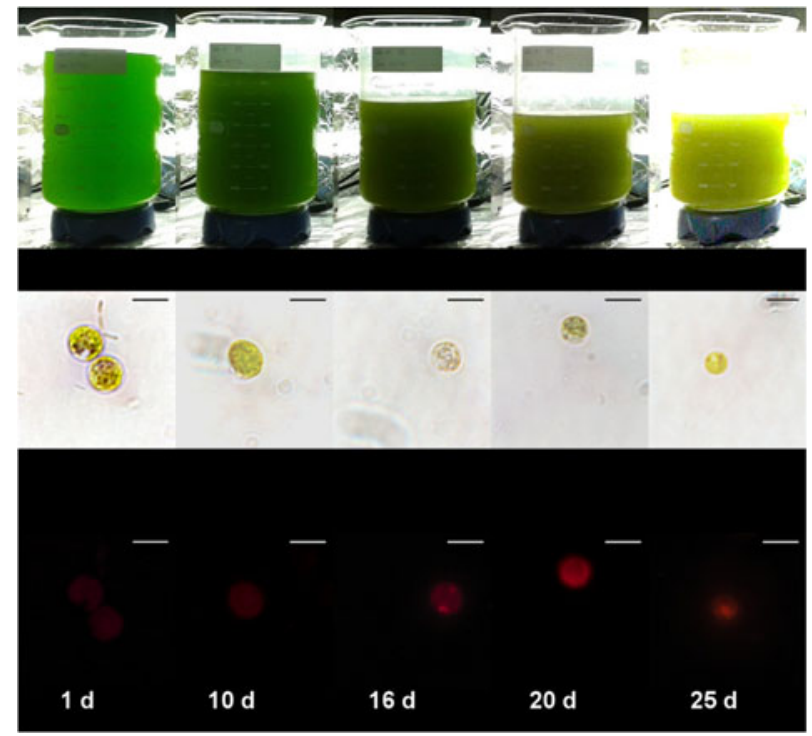
protein decreased significantly in comparison to cells grown in $\mathrm{N}$ - and P-rich culturing media [42]. Contrary to these studies, it was found that carbohydrate content of Dunaliella parva was significantly reduced in response to P limitation [43], which clearly emphasizes that the expected effects of stress-induced nutrient limitations on biochemical cellular composition are species dependent and not fully comprehended (Table 2).

Lipid accumulation in the microalgae polyculture consortium utilized in this work was significantly higher $(p<0.001)$ only when cells were transferred to $\mathrm{N}$ - and P-limited medium (Table 4). Under these growth conditions, lipid content was 5-fold higher increasing notably from $3 \pm 0.5$ to $16.3 \pm 0.8 \%$ (Fig. 2b). Incremental lipid accumulation of 3.7-fold in Chlorella protothecoides [18] and 2.2-fold in C. vulgaris [29] was also reported to occur under N- and Plimiting conditions. It is worth mentioning that cells became yellowish throughout the experimental time frame in the absence of these nutrients (Fig. 3), possibly due to conversion of chlorophyll into lipids [14]. The intracellular lipid accumulation over time in cells of Chlorella spp. was supported by microscopy analyses of cells stained with specific neutral lipid Nile red dye (Fig. 3).

\section{Conclusions}

Microalgae polyculture dominated by Chlorella spp. harvested from phycoremediation of nutrient-rich swine wastewater digestate showed high protein and carbohydrate content at the expenses of lipids. Nonetheless, it seems that carbohydrates and lipid contents can be significantly improved by straightforward operational process controlling $\mathrm{N}$ and $\mathrm{P}$ availability. Only in the absence of both $\mathrm{N}$ and $\mathrm{P}$, lipid content increased from 3 to $16 \%$. Incremental lipid content can be particularly relevant for biodiesel industries as well as several other companies interested in the commercial value of algae-derived oil by-products. Regarding to harvesting methods, coagulation-flocculation with tannin led to lower protein and lipid amounts and higher carbohydrate content as compared to centrifugation. Further studies are required, however, to scrutinize the potential effects of harvesting methods on the physiology of microalgae biochemical composition changes.

Acknowledgments This research was supported by CAPES-EMBRAPA (\#001/2011) and EMBRAPA (\#02.12.08.004.00.05). We thank Dr. Mariana Groke for the photomicrographs and Dr. Bruno dos Santos A. F. Brazil for microalgae identification.

\section{References}

1. Mezzari, M. P., Da Silva, M. L. B., Nicoloso, R. S., Ibelli, A. M. G., Bortoli, M., Viancelli, A., \& Soares, H. M. (2013). Assessment of $\mathrm{N}_{2} \mathrm{O}$ emission from a photobioreactor treating ammonia-rich swine wastewater digestate. Bioresource Technology, 149, 327-332. doi:10.1016/j.biortech.2013.09.065.

2. Wang, H., Xiong, H., Hui, Z., \& Zeng, X. (2012). Mixotrophic cultivation of Chlorella pyrenoidosa with diluted primary piggery wastewater to produce lipids. Bioresource Technology, 104, 215-220. doi:10.1016/j. biortech.2011.11.020.

3. Prajapati, S. K., Kaushik, P., Malik, A., \& Vijay, V. K. (2013). Phycoremediation and biogas potential of native algal isolates from soil and wastewater. Bioresource Technology, 135, 232-238.

4. Choi, H. J., Seung, C., \& Lee, M. (2014). Effect of the N/P ratio on biomass productivity and nutrient removal from municipal wastewater. Bioprocess and Biosystems Engineering, 38, 761-766. doi:10.1007/ s00449-014-1317-z. 
5. Choi, H. J. (2014). Effect of optical panel distance in a photobioreactor for nutrient removal and cultivation of microalgae. World Journal of Microbiology and Biotechnology, 30, 2015-2023. doi:10.1007/s11274-014-1626-z.

6. Gupta, P. L., \& Choi, S. L. H. (2015). A mini review: photobioreactors for large scale algal cultivation. World Journal of Microbiology and Biotechnology, 31(9), 1409-1417. doi:10.1007/s11274-015-1892-4.

7. Rasala, B. A., \& Mayfield, S. P. (2014). Photosynthetic biomanufacturing in green algae: production of recombinant proteins for industrial, nutritional, and medical uses. Photosynthesis Research, 123(3), 227-239.

8. Zhu, S., Huang, W., Xu, J., Wang, Z., Xu, J., \& Yuan, Z. (2014). Metabolic changes of starch and lipid triggered by nitrogen starvation in the microalga Chlorella zofingiensis. Bioresource Technology, 152, 292298. doi:10.1016/j.biortech.2013.10.092.

9. Ho, S. H., Huang, S. W., Chen, C. Y., Hasunuma, T., Kondo, A., \& Chang, J. S. (2013). Characterization and optimization of carbohydrate production from an indigenous microalga Chlorella vulgaris FSP-E. Bioresource Technology, 135, 157-165.

10. Ho, S. H., Chen, C. Y., \& Chang, J. S. (2012). Effect of light intensity and nitrogen starvation on $\mathrm{CO}_{2}$ fixation and lipid/carbohydrate production of an indigenous microalga Scenedesmus obliquus CNW-N. Bioresource Technology, 113, 244-252.

11. Khalil, Z. I., Asker, M. M. S., El-Sayed, S., \& Kobbia, I. A. (2010). Effect of pH on growth and biochemical responses of Dunaliella bardawil and Chlorella ellipsoidea. World Journal of Microbiology and Biotechnology, 26(7), 1225-1231.

12. Roleda, M. Y., Slocombe, S. P., Leakey, R. J. G., Day, J. G., Bell, E. M., \& Stanley, M. S. (2013). Effects of temperature and nutrient regimes on biomass and lipid production by six oleaginous microalgae in batch culture employing a two-phase cultivation strategy. Bioresource Technology, 129, 439-449.

13. Ruangsomboon, S., Ganmanee, M., \& Choochote, S. (2013). Effects of different nitrogen, phosphorus, and iron concentrations and salinity on lipid production in newly isolated strain of the tropical green microalga, Scenedesmus dimorphus KMITL. Journal of Applied Phycology, 25(3), 867-874.

14. Sun, X., Cao, Y., Xu, H., Liu, Y., Sun, J., Qiao, D., \& Cao, Y. (2014). Effect of nitrogen-starvation, light intensity and iron on triacylglyceride/carbohydrate production and fatty acid profile of Neochloris oleoabundans HK-129 by a two-stage process. Bioresource Technology, 155, 204-212. doi:10.1016/j. biortech.2013.12.109.

15. Lowrey, J., Brooks, M. S., \& McGinn, P. J. (2014). Heterotrophic and mixotrophic cultivation of microalgae for biodiesel production in agricultural wastewaters and associated challenges. Journal of Applied Phycology, 27(4), 1-14. doi:10.1007/s10811-014-0459-3.

16. Lee, S. J., Kim, S. B., Kim, J. E., Kwon, G. S., Yoon, B. D., \& Oh, H. M. (1998). Effects of harvesting method and growth stage on the flocculation of the green alga Botryococcus braunii. Letters in Applied Microbiology, 27(1), 14-18.

17. Liang, K., Zhang, Q., Gu, M., \& Cong, W. (2013). Effect of phosphorus on lipid accumulation in freshwater microalga Chlorella sp. Journal of Applied Phycology, 25(1), 311-318.

18. Li, Y., Han, F., Xu, H., Mu, J., Chen, D., Feng, B., \& Zeng, H. (2014). Potential lipid accumulation and growth characteristic of the green alga Chlorella with combination cultivation mode of nitrogen $(\mathrm{N})$ and phosphorus (P). Bioresource Technology, 174, 24-32. doi:10.1016/j.biortech.2014.09.142.

19. Coward, T., Lee, J. G. M., \& Caldwell, G. S. (2014). Harvesting microalgae by CTAB-aided foam flotation increases lipid recovery and improves fatty acid methyl ester characteristics. Biomass and Bioenergy, 67, 354-362.

20. Borges, L., Morón-Villarreyes, J. A., D’Oca, M. G. M., \& Abreu, P. C. (2011). Effects of flocculants on lipid extraction and fatty acid composition of the microalgae Nannochloropsis oculata and Thalassiosira weissflogii. Biomass and Bioenergy, 35(10), 4449-4454.

21. Bonato, A.L.V., do Valle, C.B., Jank, L., Resende, R.M.S., \& Leguizamon, G.O.C. (2002). Extração de DNA genômico de Brachiaria e Panicum maximum. Campo Grande, MS, BRAZIL. doi: ISSN 1516-9308.

22. White, T. J., Bruns, T., Lee, S., \& Taylor, J. (1990). Amplification and direct sequencing of fungal ribosomal RNA genes for phylogenetics. PCR protocols: a guide to methods and applications, 18, 315-322.

23. Koetschan, C., Hackl, T., Müller, T., Wolf, M., Förster, F., \& Schultz, J. (2012). ITS2 database IV: interactive taxon sampling for internal transcribed spacer 2 based phylogenies. Molecular Phylogenetics and Evolution, 63(3), 585-588. doi:10.1016/j.ympev.2012.01.026.

24. Hall, J. D., Fucikova, K., Lo, C., Lewis, L. A., \& Karol, K. G. (2010). An assessment of proposed DNA barcodes in freshwater green algae. Cryptogamie Algologie, 31(4), 529-555.

25. APHA. (2012). Standard methods for the examination for water and wastewater. (D. American Water Works Association, Washington, Ed.) (22 ${ }^{\text {nd }}$ Ed.).

26. Porra, R. J., Thompson, W. a., \& Kriedemann, P. E. (1989). Determination of accurate extinction coefficients and simultaneous equations for assaying chlorophylls $a$ and $b$ extracted with four different solvents: verification of the concentration of chlorophyll standards by atomic absorption spectroscopy. Biochimica et Biophysica Acta (BBA) - Bioenergetics, 975(3), 384-394. doi:10.1016/S0005-2728(89)80347-0. 
27. Held, P., \& Raymond, K. (2011). Determination of algal cell lipids using Nile red — using microplates to monitor neutral lipids in Chlorella vulgaris. Biofuel Research, 8, 1-5.

28. Mezzari, M. P., da Silva, M. L. B., Pirolli, M., Perazzoli, S., Steinmetz, R. L. R., Nunes, E. O., \& Soares, H. M. (2014). Assessment of a tannin-based organic polymer to harvest Chlorella vulgaris biomass from swine wastewater digestate phycoremediation. Water Science and Technology, 70(5), 888-894.

29. Chu, F. F., Chu, P. N., Cai, P. J., Li, W. W., Lam, P. K. S., \& Zeng, R. J. (2013). Phosphorus plays an important role in enhancing biodiesel productivity of Chlorella vulgaris under nitrogen deficiency. Bioresource Technology, 134, 341-346.

30. Chu, F. F., Chu, P. N., Shen, X. F., Lam, P. K. S., \& Zeng, R. J. (2014). Effect of phosphorus on biodiesel production from Scenedesmus obliquus under nitrogen-deficiency stress. Bioresource Technology, 152, 241246.

31. Ho, S. H., Nakanishi, A., Ye, X., Chang, J. S., Hara, K., Hasunuma, T., \& Kondo, A. (2014). Optimizing biodiesel production in marine Chlamydomonas sp. JSC4 through metabolic profiling and an innovative salinity-gradient strategy. Biotechnology for Biofuels, 7(1), 97. doi:10.1186/1754-6834-7-97.

32. Roopnarain, A., Gray, V. M., \& Sym, S. D. (2014). Phosphorus limitation and starvation effects on cell growth and lipid accumulation in Isochrysis galbana U4 for biodiesel production. Bioresource Technology, $156,408-411$.

33. AOCS. (2013). Official methods and recommended practices of the AOCS. (D. Firestone, Ed.) (6th ed.). Champaign: American Oil Chemists' Society.

34. AOAC. (1990). Official methods of analysis of AOAC International. (Kenneth Helrich, Ed.) (15th ed.). Washington: Association of Official Analytical Chemists.

35. BCAA. (2009). Ash or mineral matter. In Brazilian Compendium of Animal Nutrition (p. 204). São José do Rio Preto, SP, Brazil.

36. Bi, Z., \& He, B. B. (2013). Characterization of microalgae for the purpose of biofuel production. Transactions of the ASABE, 56(4), 1529-1539.

37. Pancha, I., Chokshi, K., George, B., Ghosh, T., Paliwal, C., Maurya, R., \& Mishra, S. (2014). Nitrogen stress triggered biochemical and morphological changes in the microalgae Scenedesmus sp. CCNM 1077. Bioresource Technology, 156, 146-154. doi:10.1016/j.biortech.2014.01.025.

38. Ikaran, Z., Suárez-Alvarez, S., Urreta, I., \& Castañon, S. (2015). The effect of nitrogen limitation on the physiology and metabolism of Chlorella vulgaris var L3. Algal Research, 10, 134-144. doi:10.1016/j.algal. 2015.04.023.

39. Bondioli, P., Della Bella, L., Rivolta, G., Chini Zittelli, G., Bassi, N., Rodolfi, L., Casini, D., Prussi, M., Chiaramonti, D., \& Tredici, M. R. (2012). Oil production by the marine microalgae Nannochloropsis sp. F\&M-M24 and Tetraselmis suecica F\&M-M33. Bioresource Technology, 114, 567-572.

40. Peccia, J., Haznedaroglu, B., Gutierrez, J., \& Zimmerman, J. B. (2013). Nitrogen supply is an important driver of sustainable microalgae biofuel production. Trends in Biotechnology, 31(3), 134-138.

41. Bellou, S., Baeshen, M. N., Elazzazy, A. M., Aggeli, D., Sayegh, F., \& Aggelis, G. (2014). Microalgal lipids biochemistry and biotechnological perspectives. Biotechnology Advances, 32(6), 1476-1493. doi:10.1016/j. biotechadv.2014.10.003.

42. Zhao, Y., Yu, Z., Song, X., \& Cao, X. (2009). Biochemical compositions of two dominant bloom-forming species isolated from the Yangtze River Estuary in response to different nutrient conditions. Journal of Experimental Marine Biology and Ecology, 368(1), 30-36.

43. Said, H. A. (2009). Changes in levels of cellular constituents of Dunaliella parva associated with inorganic phosphate depletion. Middle-East Journal of Scientific Research, 4(2), 44-49. 